\title{
C1C2 Distraction and Compression Technique for Craniovertebral Junction Anomalies with Basilar Invagination and Irreducible Atlantoaxial Dislocation
}

\author{
Vamsi Krishna Yerramneni ${ }^{1}$ Vamshi Krishna Kotha ${ }^{1}$ Ramanadha Reddy ${ }^{1}$ \\ ${ }^{1}$ Department of Neurosurgery, Nizam's Institute of Medical \\ Sciences, Punjagutta, Hyderabad, Andhra Pradesh, India

\begin{abstract}
Address for correspondence Vamsi Krishna Yerramneni, MBBS, MS, Department of Neurosurgery, Nizam's institute of Medical Sciences, Punjagutta, Hyderabad 500082, Andhra Pradesh, India

(e-mail: vamsiky.ns@gmail.com).
\end{abstract}

Indian J Neurosurg 2018;7:184-189
Abstract
Keywords
- basilar invagination
- craniovertebral junc- tion anomaly
- irreducible atlantoaxial dislocation

The authors describe four cases of basilar invagination (BI) with irreducible atlantoaxial dislocation (AAD) by distraction and compression technique. The article describes the technique in detail and the principles of the reduction achieved in all the planes by C1C2 screw placement, the cage insertion in the C1C2 joint, and manipulation of the joint. They described in the literature well-discussed various modifications and their application for treatment of BI with irreducible AAD.

\section{Introduction}

The craniovertebral junction (CVJ) anomaly treatment underwent paradigm shift in the management in the past two decades. From transoral decompression and posterior fixations to only posterior approaches with $\mathrm{C} 1 \mathrm{C} 2$ fixations with complete restoration of normal alignment at the joints have become the norm now. ${ }^{1-5}$ Goel et al pioneered and popularized the technique of atlantoaxial fixations (C1C2 fixation), minimizing the need for transoral decompression. ${ }^{3,4}$ Continuing further with the modifications in the surgical procedures, Chandra et al developed the novel technique of distraction, compression, and extension reduction (DCER) for the complex anomalies associated with basilar invagination (IB) and atlantoaxial dislocation (AAD) further obviating the need for transoral decompression. ${ }^{5,6}$ The DCER technique involved occiput to $\mathrm{C} 2$ fusion and the further maneuvers for achieving proper alignment at the $\mathrm{C} 1 \mathrm{C} 2$ joint. However, the occipitocervical fusions have the inherent disadvantages of restricting the neck movements to a major extent. The authors in this article described a novel technique involving $\mathrm{C} 1 \mathrm{C} 2$ fixations and subsequent manipulations of distractions and compression to achieve alignment at the DCER to achieve.

\section{Materials and Methods}

The study population included the patients with CVJ anomaly who had the $\mathrm{C} 1 \mathrm{C} 2$ fixation with joint distraction and manipulations to achieve alignment of the $\mathrm{C} 1 \mathrm{C} 2$ joint. Patients with CVJ anomalies having BI and the fixed AAD were included in the study.

\section{Study Design}

This is a retrospective observational study.

\section{Preoperative Clinical Features and Evaluation}

Preoperative evaluation included clinical assessment in the pre- and postoperative period as per Nurick's grading. ${ }^{7}$

Each patient had magnetic resonance imaging (MRI) of the $\mathrm{CVJ}$ and computed tomography (CT) of the CVJ in flexion and extension with reconstruction in coronal and sagittal planes and the $\mathrm{CT}$ angio of the vertebral artery to enable the better assessment of the CVJ anatomy.

Especially size of the lateral masses of $\mathrm{C} 1$ and the pedicles of C2 measurements and also to look for any anomalous course of the vertebral artery, if exists, were noted preoperatively. received

February 13, 2018

accepted

March 23, 2018

published online

May 14, 2018
DOI https://doi.org/

$10.1055 / s-0038-1649333$.

ISSN 2277-954X.
(C)2018 Neurological Surgeons'

Society of India
License terms

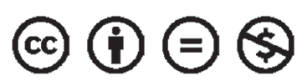


The traditional indices such as Wackenheim clival canal line (normal being $0.96+2.2 \mathrm{~mm}$ below this line), Chamberlain line (normal being $2.36+2.6 \mathrm{~mm}$ below this line), McRae line $(5.86+1.6 \mathrm{~mm}$ below this line), and modified Ranawat line (normal $29.76+2.6 \mathrm{~mm}$ ) were used as criteria for diagnosing $\mathrm{BI}^{8-10}$

\section{Presurgical Planning}

All patients underwent $\mathrm{C} 1 \mathrm{C} 2$ fixation and $\mathrm{C} 1 \mathrm{C} 2$ joint opening followed by insertion of the metallic cages and the manipulations of the $\mathrm{C} 1$ and $\mathrm{C} 2$ to achieve reduction.

\section{Operative Technique}

Patients were intubated using the fiberoptic laryngoscope. They were positioned prone with head in neutral position over the horseshoe head rest. Cervical traction of 5 to $7 \mathrm{~kg}$ was applied in all the cases using Gardner Well Tongs. Traction ensured the distraction at the $\mathrm{C} 1 \mathrm{C} 2$ joint rendering the $\mathrm{C} 1$ lateral mass and the $\mathrm{C} 1 \mathrm{C} 2$ joint access easier. It also helps in minimizing the venous congestion at the CVJ.

Midline skin incision from below inion up till C3 was given, and subsequent muscle detachment and dissection was done to expose the $\mathrm{C} 1$ posterior arch and C2 lamina up till the facets laterally.

As an initial step in cases of the occipitalized $\mathrm{C} 1$ arch and the foramen magnum rim compressing the cervicomedullary junction, excision of the $\mathrm{C} 1$ arch in addition to the rim of the foramen magnum, if necessary, was done. This facilitated the visualization the $\mathrm{C} 1$ lateral masses for screw placement in an otherwise crowded foramen magnum as a result of the BI. This decompression also prevents any inadvertent injury to the already compromised cervicomedullary junction during manipulations at the $\mathrm{C} 1 \mathrm{C} 2$ joint subsequently.

The authors avoided resecting the $\mathrm{C} 2$ ganglion, by dealing with the bleeding around using bipolar coagulation of venous plexus around it and retraction of the ganglion to gain working space around the $\mathrm{C} 1 \mathrm{C} 2$ joint.

The posterior surface of the C1 Lateral mass was exposed and the midpoint was chosen as the entry point for the screw. A $3.5 \mathrm{~mm}$ diameter and 18 to $22 \mathrm{~mm}$ length were inserted 15 degrees medial and 15 degrees cranial under fluoroscopic guidance until the screw tip reached the anterior cortex of the lateral mass.

C2 screw of similar size as that used in C1 was inserted with the entry point $5 \mathrm{~mm}$ rostral and $1 \mathrm{~mm}$ medial to the inferomedial aspect of the inferior articulating surface and directed 25 to 30 degrees medially and 10 to 15 degrees cranially.

The $\mathrm{C} 1 \mathrm{C} 2$ joints were initially probed with a blunt dissector, followed by periosteal elevator or a chisel with its broad tip parallel to the articular surfaces during insertion, subsequently rotating it by 90 degrees, thereby wide opening the joint. The articular surfaces are then scraped with curettes. In cases of vertically aligned joints, engagement of the rod is done on one side and distracted to get partial correction of the rotatory subluxation, which can help in engaging the cage snugly between the joint surfaces of other side followed by rod placement. Even after the placement of the rod, the joint can be accessed in an oblique direction easily for inserting a cage. These simple tricks help engage cages in the $\mathrm{C} 1 \mathrm{C} 2$ joints with vertical alignment. Then the cages filled with bone chips are impacted into the disc space. We use cuboid-shaped cervical cages of 5 to $9 \mathrm{~mm}$ (manufactured by General Surgical Company [India] Private Ltd.) based on the degree of BI. This achieves the reduction in the BI.

Slight lordosis is given to the rods before placement in the screw heads. Compression of the screw heads is done with the compressor tool to close the gap between the screw heads almost ending them touching each other. This maneuver brings in posterior translation of the $\mathrm{C} 1 \mathrm{arch}$ and anterior translation of the odontoid peg, resulting in the reduction in the AAD.

Remaining bone chips are placed around the $\mathrm{C} 1 \mathrm{C} 2$ joint space and closure is done.

\section{Case 1}

A young 21-year-old man presented to our services with paraesthesia all over the body below the neck level and spasticity and resulting difficulty in walking for 6 months. The patient had occipitocervical fusion (OCF) for BI with fixed AAD at another neurosurgical center. Neurologic examination revealed spastic quadriparesis, short neck, and other features of high cervical myelopathy.

X-ray, MRI, and CT of the CVJ showed features of BI with fixed AAD ( - Fig. 1a). OCF construct removal and foramen magnum decompression were performed followed by $\mathrm{C} 1$ lateral mass and $\mathrm{C} 2$ pedicle screw placement. C1C2 joint opening and cage placements and subsequent compression of the $\mathrm{C} 1 \mathrm{C} 2$ screws over the rod achieved the reduction in the BI and AAD ( - Fig. 1b-e). The patient reported improvement in symptoms from postoperative day 1 , and at 6 months follow-up his Nurick's grade improved from grade 4 to 2 .

\section{Case 2}

A 42-year-old male patient presented with torticollis since childhood had a trivial trauma as a result of fall and fell unconscious for 10 minutes. Since then he started having neck pain, tingling, and paraesthesia all over the body. He gradually developed spastic quadriparesis and required assistance for walking. He improved Nurick's grade from 4 to 2 with in the first week of surgery.

X-ray, MRI, and CT of the CVJ demonstrated a BI with irreducible AAD (- Fig. 2a).

The patient underwent foramen magnum decompression and following that a $\mathrm{C} 1 \mathrm{C} 2$ screw placement on the right side and $\mathrm{C} 1 \mathrm{C} 3$ screw placement on the left side as the $\mathrm{C} 2$ pedicle was thin, and there was injury to the vertebral artery during the attempted screw placement. Distraction and compression after cage placement resulted in normal alignment at the CVJ ( - Fig. 2b).

\section{Case 3}

A young 15-year-old male patient had BI with AAD presented with high cervical compressive myelopathy symptoms had C1C2 fixation at another center presented to us with no improvement in symptoms after surgery. He was reoperated, C1 

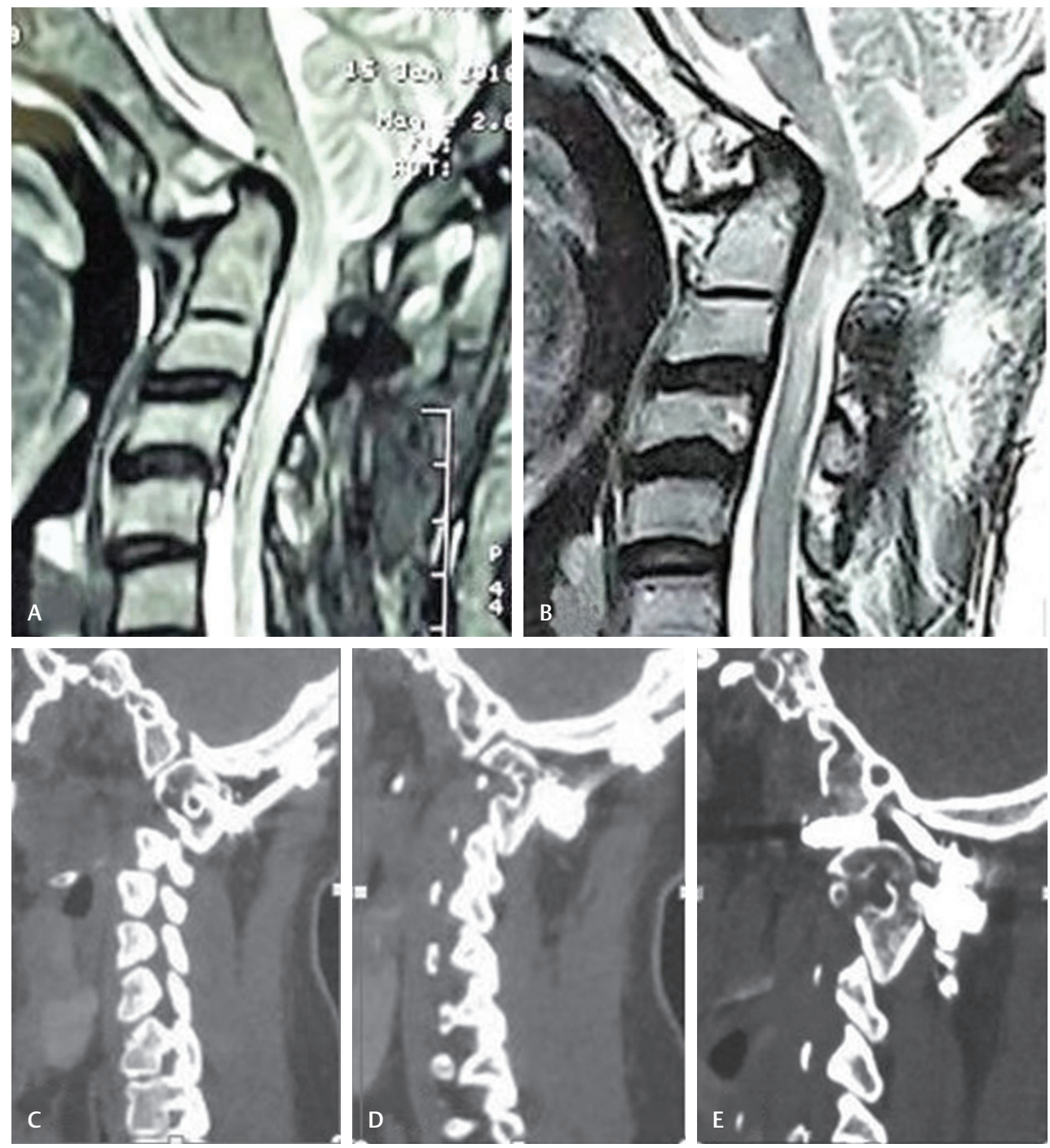

Fig. 1 Case1: (a) MRI sagittal section showing BI with AAD and anterior obliteration of the CSF column at CMJ. (b) Postoperative CT showing reduced $\mathrm{BI}$ and CSF column anteriorly visible at CMJ. (c, d) Preoperative images of CT sagittal section at facet level showing C1C2 joint alignment and (e) showing corrected alignment at C1C2 after surgery.

screw readjustment and cage placement were done with dis-

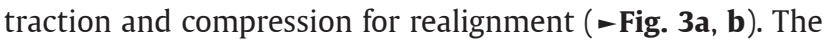
patient reported improvement of symptoms the next day. His preoperative Nurick's grade was 4 and postoperatively it improved to 2 .

\section{Case 4}

A 40-year-old man with neck pain and compressive myelopathy symptoms at the CVJ with BI and AAD had restoration of the alignment at the CVJ with C1 and C2 fixation, distraction, and compression. The patient reported improvement in symptoms on postoperative day 1. (- Fig. 4a, b). He improved from Nurick's grade 5 to 2 postoperatively.

\section{Discussion}

The CVJ anomaly treatment has undergone phenomenal change with pioneering work by Goel et al., ${ }^{3,11,12}$ The entire focus is now on atlantoaxial screw placement with joint manipulations. , $, 6,11-17^{-17}$
The complex CVJ anomalies with BI and irreducible or fixed AAD have dislocation in sagittal and coronal alignment with some rotational component in addition. ${ }^{12,13}$ Salunke et al proposed that correction in one plane of the joint can well result in the corrections in the other planes. ${ }^{13}$

Because the paradigm shift that has happened after pioneering work by Goel et al, many modifications and additions for the techniques have come up over time. Technique by Goel et al advocates $\mathrm{C} 1 \mathrm{C} 2$ screw placement and opening of the joint with chisel and manipulating it to place spacer or strut bone graft to achieve the alignment at the $\mathrm{C} 1 \mathrm{C} 2$ joint. The spacer size inserted in the joint space depends on the extent of the possible distraction.

Chandra et al proposed the DCER involves the distraction of joint space with spacers (in the occipito-C1/C2 joint space) followed by compression between the occiput and $\mathrm{C} 2$, leading to extension at the $\mathrm{O}-\mathrm{C} 1 / \mathrm{C} 2$ joint, which in turn leads to reduction in $\mathrm{AAD}$ and complete remodeling of the joint. The technique of distraction compression and reduction reduces the anteroposterior dislocation along with the vertical 

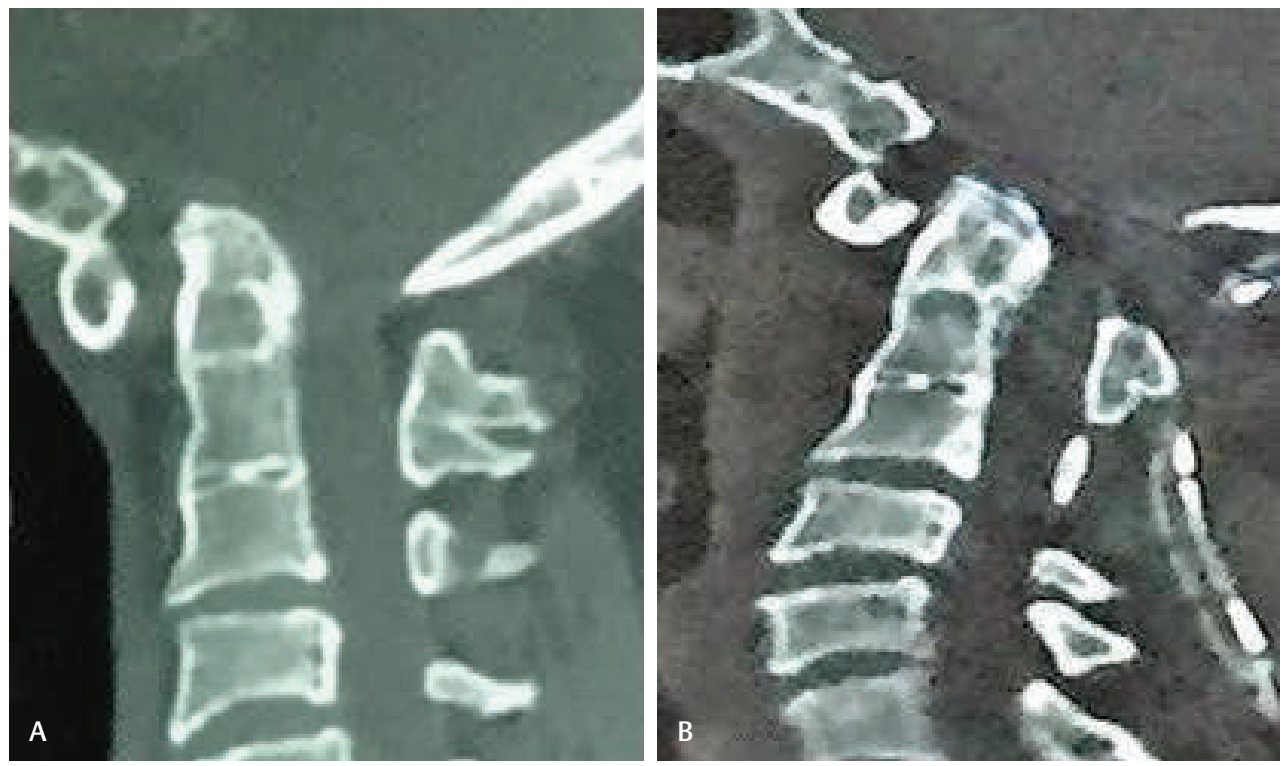

Fig. 2 Case 2: (a) CT sagittal sequence showing BI with AAD. (b) Postoperative CT showing reduction in BI and AAD.
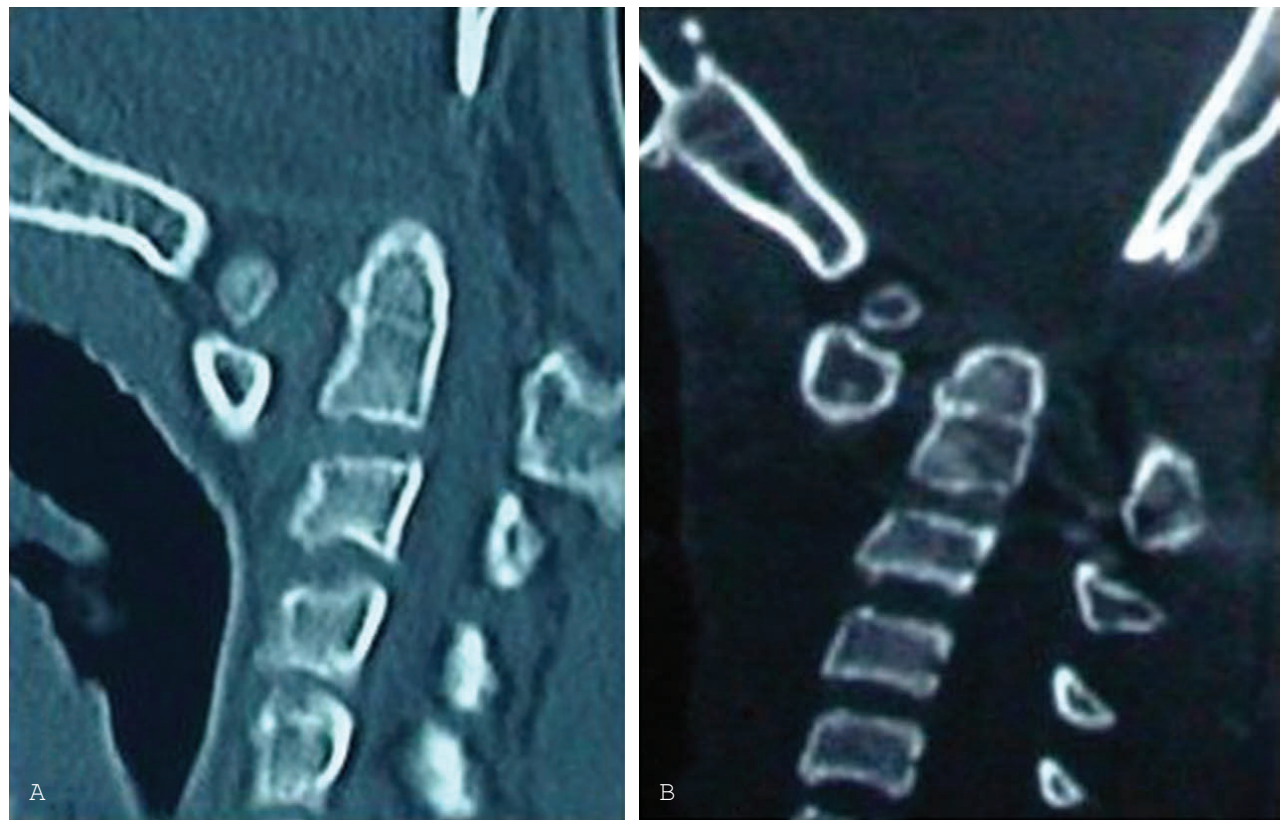

Fig. 3 Case 3: (a) CT sagittal sequence with AAD and BI with Os odontoideum. (b) Postoperative images of CT showing reduction in BI and AAD with foramen magnum drilled.

dislocation. This uses the spacer as a fulcrum and C2 laminar screws as long lever.

This compilation of cases by the authors is unique in the sense that the technique used is essentially C1C2 fixation and the principles of DCER for reduction. In cases with atrophic C1 lateral mass on one side resulting in torticollis, cages of different sizes were used. Even in cases in which the C1C2 joint line is vertical, the engagement of the cage in the joint is possible after the joint opening and engagement of the rod in the screw heads on one side, which results in partial restoration of the alignment in all three dimensions. The authors believe that the foramen magnum decompression in cases of occipitalized C1 arch impinging posteriorly on the cervicomedullary junction prior to all manipulations is advisable to prevent the inadvertent injury during manipulation.

Slight lordosis of the rod combined with compression of the screw heads to achieve near approximation results in the attainment of the proper alignment at C1C2 joint. Engagement of the rod in the screw heads itself corrects the rotational alignment to an extent with the rest of the correction happening when the compression of the screw heads is done over the rod. This alignment restoration happens much like 

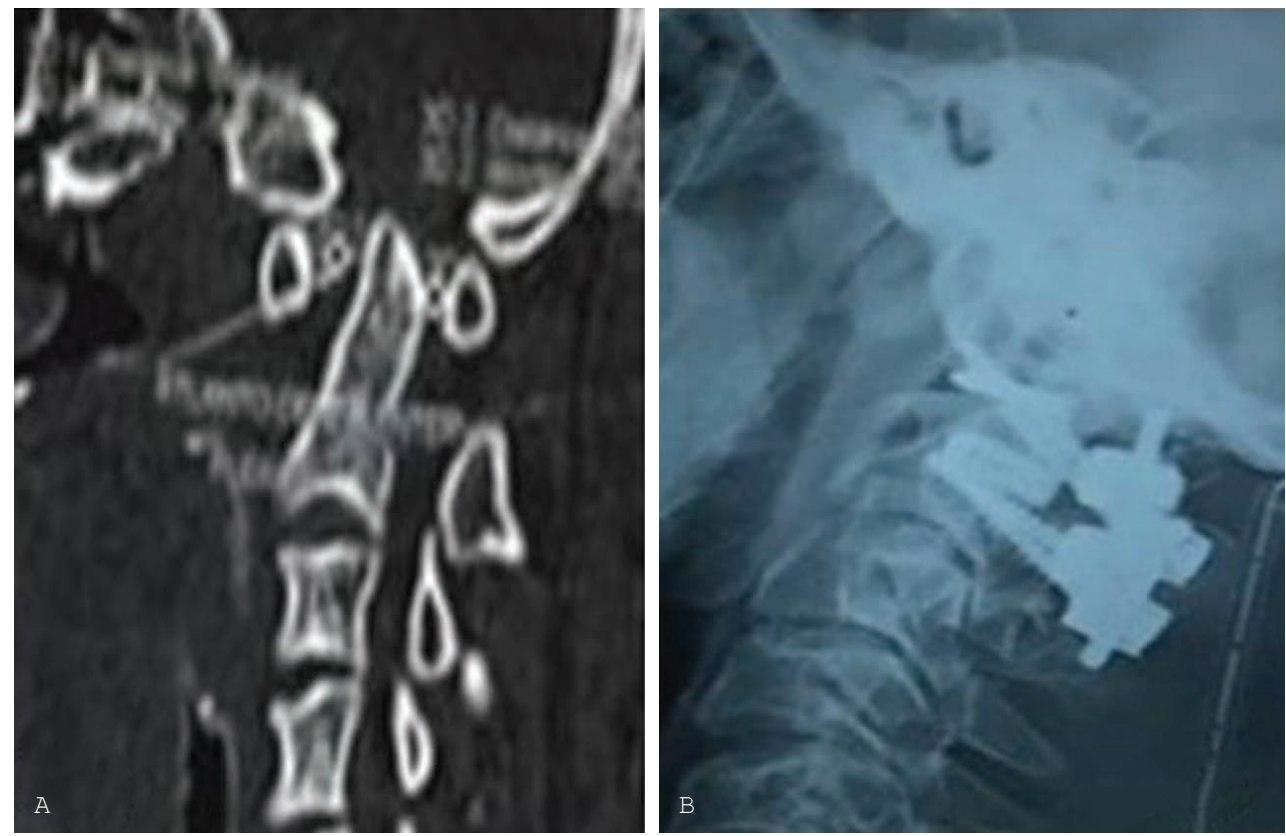

Fig. 4 Case4: (a) BI with AAD on CT sagittal section. (b) Patient's postoperative X-ray of CVJ showing cages in the C1C2 joint, and it demonstrates the screw heads almost touching each other after compression of the screw heads leading to reduction in the AAD.

what happens in scoliosis correction of the spine when the engagement of the rod is done in the screw heads following osteotomies rendering the vertebral segments mobile.

Therefore, the authors believe that opening of the joint and ability to engage a cage in the joint with manipulations and maneuvers using a chisel as described by Goel ${ }^{12}$ and adding a compression of the screw heads of $\mathrm{C} 1 \mathrm{C} 2$ as described by Chandra et $\mathrm{al}^{5}$ over a lordotic rod do the entire job for restoration of the alignment at $\mathrm{CVJ}$.

The recent reports by Chandra et al and Saluke et al advocated the drilling of joints to insert cages. ${ }^{6,17-19}$ Though this is a small series, the authors demonstrated achieving the alignment without the need for drilling the joint. In addition, drilling the joint is technically more cumbersome and also theoretically it carries the prospect of subsidence of the cage into the lateral mass of the $\mathrm{C} 1$ keeping in view the fact that the strong cortical surface is rendered weak by drilling.

The authors also have considerable experience in using this technique of placing spacers in the $\mathrm{C} 1 \mathrm{C} 2$ joint in cases with partially reducible AAD to achieve a good alignment at the CVJ.

Though the number of patients included in the study was less, the authors could arrive at the aforementioned conclusions because of the long experience of treating these complicated anomalies involving manipulation of the $\mathrm{C} 1 \mathrm{C} 2$ joint.

\section{Conclusion}

The treatment of CVJ anomalies involving BI with fixed AAD has changed with the $\mathrm{C} 1 \mathrm{C} 2$ joint realignment techniques. A combination of the $\mathrm{C} 1 \mathrm{C} 2$ screw placement, followed by joint opening, subsequent distraction, and compression of the screw heads can achieve the alignment at the CVJ. These maneuvers have the potential to correct the alignment in all planes of the $\mathrm{C} 1 \mathrm{C} 2$ joint, including the rotational component.

\section{Conflict of Interest}

None.

\section{References}

1 Menezes AH. Craniovertebral junction anomalies: diagnosis and management. Semin Pediatr Neurol 1997;4(3):209-223

2 Goel A, Bhatjiwale M, Desai K. Basilar invagination: a study based on 190 surgically treated patients. J Neurosurg 1998; 88(6):962-968

3 Goel A, Laheri V. Plate and screw fixation for atlanto-axial subluxation. Acta Neurochir (Wien) 1994;129(1-2):47-53

4 Goel A, Desai KI, Muzumdar DP. Atlantoaxial fixation using plate and screw method: a report of 160 treated patients. Neurosurgery 2002;51(6):1351-1356, discussion 1356-1357

5 Chandra PS, Kumar A, Chauhan A, Ansari A, Mishra NK, Sharma BS. Distraction, compression, and extension reduction of basilar invagination and atlantoaxial dislocation: a novel pilot technique. Neurosurgery 2013;72(6):1040-1053, discussion 1053

6 Chandra PS, Prabhu M, Goyal N, Garg A, Chauhan A, Sharma BS. Distraction, compression, extension, and reduction combined with joint remodeling and extra-articular distraction: description of 2 new modifications for its application in basilar invagination and atlantoaxial dislocation: prospective study in 79 cases. Neurosurgery 2015;77(1):67-80, discussion 80

7 Nurick S. The pathogenesis of the spinal cord disorder associated with cervical spondylosis. Brain 1972;95(1):87-100

8 Smith JS, Shaffrey CI, Abel MF, Menezes AH. Basilar invagination. Neurosurgery 2010;66(3, Suppl):39-47

9 Teodori JB, Painter MJ. Basilar impression in children. Pediatrics 1984;74(6):1097-1099

10 Wadia NH. Myelopathy complicating congenital atlanto-axial dislocation. (A study of 28 cases.) Brain 1967;90(2):449-472

11 Goel A, Kulkarni AG, Sharma P. Reduction of fixed atlantoaxial dislocation in 24 cases: technical note. J Neurosurg Spine 2005;2(4):505-509 
12 Goel A. Treatment of basilar invagination by atlantoaxial joint distraction and direct lateral mass fixation. J Neurosurg Spine 2004;1(3):281-286

13 Salunke P, Sharma M, Sodhi HB, Mukherjee KK, Khandelwal NK. Congenital atlantoaxial dislocation: a dynamic process and role of facets in irreducibility. J Neurosurg Spine 2011;15(6):678-685

14 Jian FZ, Chen Z, Wrede KH, Samii M, Ling F. Direct posterior reduction and fixation for the treatment of basilar invagination with atlantoaxial dislocation. Neurosurgery 2010;66 (4):678-687, discussion 687

15 Suh BG, Padua MR, Riew KD, et al. A new technique for reduction of atlantoaxial subluxation using a simple tool during posterior segmental screw fixation: clinical article. J Neurosurg Spine 2013;19(2):160-166
16 Yin YH, Qiao GY, Yu XG, Tong HY, Zhang YZ. Posterior realignment of irreducible atlantoaxial dislocation with C1-C2 screw and rod system: a technique of direct reduction and fixation. Spine J 2013;13(12):1864-1871

17 Chandra PS. In reply. Neurosurgery 2014;74(1):E148-E150

18 Deepak AN, Salunke P, Sahoo SK, Prasad PK, Khandelwal NK. Revisiting the differences between irreducible and reducible atlantoaxial dislocation in the era of direct posterior approach and C1-2 joint manipulation. J Neurosurg Spine 2017;26 (3):331-340

19 Salunke P, Sahoo S, Khandelwal NK, Ghuman MS. Technique for direct posterior reduction in irreducible atlantoaxial dislocation: multi-planar realignment of C1-2. Clin Neurol Neurosurg 2015;131:47-53 